\title{
RESEARCH AND DEVELOPMENT CONTROL METHOD PATHOGENIC PRION INFECTIONS SECONDARY RAW MEAT INDUSTRY
}

\section{ИССЛЕДОВАНИЕ И РАЗРАБОТКА МЕТОДА КОНТРОЛЯ ПАТОГЕННЫХ ПРИОННЫХ ИНФЕКЦИЙ ПОБОЧНОГО СЫРЬЯ МЯСНОЙ ПРОМЫШЛЕННОСТИ}

\author{
Prosekov A.Y., Kriger O.V \\ Kemerovo Technological Institute of Food Industry (University), Kemerovo, Russia
}

Ключевые слова: прионный белок, молекулярная идентификация, праймерь, амплификация.

\section{Аннотация}

Разработан высокочувствительный и специфичный метод идентификаиии патогенного прионного белка. Установлено, что фракиии водорастворимых белков говядинь и плазмы крови сельскохозяйственных животных являются нормальными прионными белками крупного рогатого скота. Выравнивание последовательностей гена патогенного и нормального прионного белка Ovisaries, показало, что нуклеотидные последовательности $\mathrm{PrP}^{c}$ и $\mathrm{PrP}^{s c}$ являются идентичными. Выбрано мышиное моноклональное антитело 15В3. Построена синтетическая последовательность, длиной 194 п.н., полученная случайным образом (ДНК-хвост). Созданная последовательность и последовательности базы данных гомологов не имеют. К синтезированному ДНК-хвосту подобраны 2 праймера размерами 20 п.н. Полученные экспериментальные данные указывают на то, что при использовании праймеров AGTCAGTCCTTGGCCTCCTT (левого) и CAGTTTCGATCCTCCTCCAG (правого) амплификацию следует проводить по следующей схеме: предварительная денатурация, $95^{\circ} \mathrm{C}, 60$ секунд, 1 изкл; денатурация, $95^{\circ} \mathrm{C}$, 30 секунд, 30 ичклов; отниг, $56^{\circ} \mathrm{C}, 60$ секунд, 30 ициклов; элонгация, $72^{\circ} \mathrm{C}, 30$ секунд, 30 ииклов, дополнительная элонгация в течение 1 ицкла продолжительностью 600 секунд. Установлена оптимальная кониентрация компонентов реакиионной смеси для проведения ПЦР. Подтверждена высокая специбичность разработанной тест-системь и олигонуклеотидных праймеров путем электрофоретического разделения образиов мясного фарша, содержащего патогенный прионный белок, а также путем сравнительного анализа результатов определения патогенного прионного белка, полученных с помощью ПЦР-тест-системы и ИФА-системы $« \mathrm{TeSeE} E^{\mathrm{rm}} »$.

\section{Введение}

При использовании мясного и побочного сырья возможно обнаружение групп заболеваний, характеризующихся прогрессирующим поражением различных отделов нервной системы и имеющих необычный генетический механизм возникновения и развития, так называемых прионных заболеваний.

Контроль качества мясного сырья в этом аспекте является новой, быстро развивающейся областью биомедицинских исследований, которая в последние годы приобрела важное научно-практическое значение [1].
Keywords: prion, molecular identification, primers, amplification.

\section{Abstract}

Highly sensitive and specific method for identification of pathogenic prion protein was developed. It was found that the water-soluble fractions of beef proteins and plasma proteins of farm animals are normal prion proteins in cattle. Aligning gene sequences of pathogenic and normal prion protein of sheep (Ovis aries) revealed that the nucleotide sequences of $P_{r} P^{c}$ and $P r P^{s c}$ are identical. Murine monoclonal antibody $15 B 3$ was selected. Synthetic sequence of 194 bps was randomly produced (DNA-tail). The produced sequence and the database sequences have no homologues. Two primer of 20 bps were selected for synthesized DNA-tail. The experimental data indicate that by using AGTCAGTCCTTGGCCTCCTT (left) and CAGTTTCGATCCTCCTCCAG (right) primers the amplification should be performed as follows: pre-denaturation, $95{ }^{\circ} \mathrm{C}$, 60 seconds, 1 cycle; denaturation, $95^{\circ} \mathrm{C}, 30$ seconds, 30 cycles; annealing, $56{ }^{\circ} \mathrm{C}$, 60 seconds, 30 cycles; elongation, $72{ }^{\circ} \mathrm{C}, 30 \mathrm{sec}-$ onds, 30 cycles, additional elongation, 1 cycle, 600 seconds. The optimum concentration of reaction mixture components for PCR was established. High specificity of the developed test system and oligonucleotide primers was confirmed by electrophoretic separation of ground beef samples containing pathogenic prion protein, as well as by comparative analysis of the results of pathogenic prion protein determination. These results were obtained using PCR test system and TeSeE ${ }^{\mathrm{mi}}$ ELISA system.

\section{Introduction}

Meat and secondary raw materials may be infected with pathogens inducing a group of diseases characterized by progressive destruction of different parts of the nervous system and possessing an unusual genetic mechanism of occurrence and development, i.e. so-called prion diseases.

In this respect, meat raw materials quality control is a new rapidly developing field of biomedical research, which has acquired great scientific and practical significance in recent years [1].

Prevention of prion diseases is based on the control and rejection of infected meat products or other products 
Профилактика прионных болезней основывается на контроле и недопущении в пищу инфицированных мясных продуктов или других продуктов убоя. Поэтому усовершенствование и разработка чувствительных, специфичных и экспрессных методов идентификации патогенной формы прионного белка являются актуальной проблемой.

Целью работы является создание высокочувствительного метода идентификации патогенной формы прионного белка.

\section{Материалы и методы}

Для анализа последовательностей ДНК, кодирующей синтез гена PRNP прионного белка, использовали базу данных NCBI, для построения филогенетического дерева использована компьютерная программа «CrustalW», подбор праймеров для амплификации специфических последовательностей патогенного прионного белка проводили с помощью программ: «NSBI Blast2», «Primer3 Output». Исследования осуществлены в соответствии с требованиями нормативно-технической документации (ГОСТ Р 52833-2007(ИСО 22174:2005) и МУ 1.3.1794-03 «Организация работы при исследованиях методом ПЦР материала, инфицированного микроорганизмами I-II групп патогенности»).

\section{Результаты и обсуждение}

Установлено, что фракции водорастворимых белков говядины и плазмы крови сельскохозяйственных животных являются нормальными прионными белками крупного рогатого скота [2].

Исследовано разнообразие в строении гена PRNP прионного белка у различных представителей крупного рогатого скота для выявления внутривидовых различий в последовательности этого гена и возможности использования результатов данного исследования при молекулярной идентификации патогенного прионного белка, конструировании универсальных праймеров для амплификации гена PRNP.

Для того, чтобы нагляднее оценить степень эволюционного родства последовательностей прионного белка, в компьютерной программе «CrustalW» было построено филогенетическое дерево, представленное на рисунке 1 .

Проведено выравнивание последовательностей гена патогенного и нормального прионного белка Ovisaries, представленное на рисунке 2, которое показало, что нуклеотидные последовательности $\operatorname{PrP}^{c}$ и $\operatorname{PrP}^{\mathrm{sc}}$ являются идентичными.

Проведенный филогенетический анализ подтвердил, что последовательности гена прионного белка являются весьма консервативными и различаются лишь конформацией и связанной с ней устойчивостью к протеолизу.

Это не позволяет выбрать ДНК-мишень из прионных последовательностей для последующего анализа с помощью ПЦР. of slaughter. Therefore, improvement and development of sensitive, specific and rapid methods for identifying pathogenic forms of prion protein is an urgent problem.

The objective of this work was to develop a highly sensitive method for identification of the pathogenic form of the prion protein.

\section{Materials and methods}

To establish the DNA sequences coding the PRNP prion protein gene, the NCBI database was used; to construct phylogenetic tree, CrustalW software was used; the selection of primers for amplification of specific sequences of a pathogenic prion protein was performed using NSBI Blast 2 and Primer3 Output software. Studies were carried out in accordance with the requirements of regulative documentation (GOST R 52833-2007 (ISO 22174: 2005) and MU 1.3.1794-03 «Work organization in studies using PCR material infected with microorganisms of I-II pathogenicity groups»).

\section{Results and discussion}

It was found that the water-soluble fractions of beef proteins and plasma proteins of farm animals are normal prion proteins in cattle [2].

The diversity in sequence of PRNP prion protein gene in various representatives of cattle was studied to detect intraspecific differences in the sequence of this gene and the possibility of using the results of this study in molecular identification of the pathogenic prion protein and development of all-purpose primers for amplification of PRNP gene.

In order to more clearly assess the degree of evolutionary congeniality of prion protein sequences, the CrustalW software was used to construct the phylogenetic tree presented in Figure 1.

The sequence alignment of pathogenic and normal prion protein genes of Ovis aries was carried out, which showed that the nucleotide sequence of $\mathrm{PrP}^{c}$ and $\mathrm{PrP}^{\mathrm{sc}}$ are identical; the results are represented in Figure 2.

The conducted phylogenetic analysis confirmed that the prion protein gene sequences are highly conservative and differ only in conformation and related resistance to proteolysis.

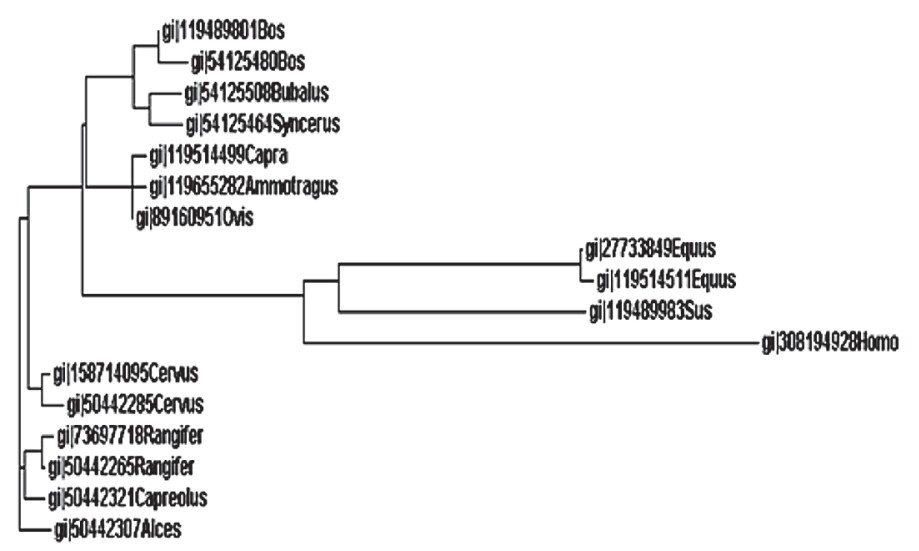

Figure 1. The phylogenetic tree of PRNP prion protein gene sequences Рис. 1. Филогенетическое дерево последовательностей гена PRNP прионного белка 
gi|341942290PrPsc GGGTCAAGGTGGTAGCCACAGTCAGTGGAACAAGCCCAGTAAGCCAAAAACCAACATGAA 60 gi|47028553PrP -GGTCAAGGTGGTAGCCACAGTCAGTGGAACAAGCCCAGTAAGCCAAAAACCAACATGAA 59

gi|341942290PrPsc GCATGTGGCAGGAGCTGCTGCAGCTGGAGCAGTGGTAGGGGGCCTTGGTGGCTACATGCT 120 gi|47028553PrP GCATGTGGCAGGAGCTGCTGCAGCTGGAGCAGTGGTAGGGGGCCTTGGTGGCTACATGCT 119

gi|341942290PrPsC GGGAAGTGCCATGAGCAGGCCTCTTATACATTTTGGCAATGACTATGAGGACCGTTACTA 180 gi|47028553PrP GGGAAGTGCCATGAGCAGGCCTCTTATACATTTTGGCAATGACTATGAGGACCGTTACTA 179

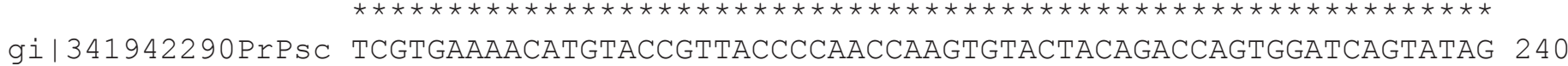
gi|47028553PrP TCGTGAAAACATGACCGTTACCCCAACCAAGTGTACTACAGACCAGTGGATCAGTATAG 239

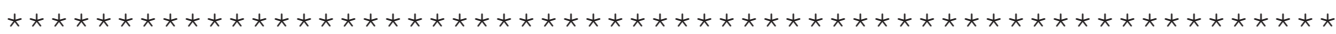

gi|341942290PrPsC AACCAGAACAACTTTGTGCATGACTGTGTCAACACCACAGTCAAGCAACACACAGTCAC 300 gi|47028553PrP TAACCAGAACAACTTTGTGCATGACTGTGTCAACATCACAGTCAAGCTACACACAGTCAC 299

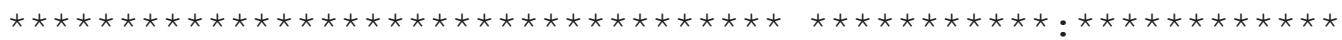

gi|341942290PrPsc CACCACCACCAAGGGGGAGAACTTCACCGAAACTGACATCAAGATAATGGAGCGAGTGGT 360 gi|47028553PrP CACCACCACCAAGGGGGAGAACTTCACCGAAACTGACATCAAGATAATGGAGCGAGTGGT 359

gi|341942290PrPsc GGAGCAAATGTGCATCACCCAGTACCAGAGAGAATCCCAGGCTT 404

gi|47028553PrP GGAGCAAATGTGCATCACCCAGTACCAGAGAGAATCCCAGGCT- 402

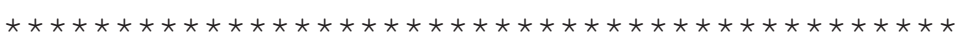

Figure 2. The alignment of nucleotide sequences of normal $\mathrm{PrP}^{\mathrm{c}}$ and pathogenic $\mathrm{PrP}^{\mathrm{sc}}$ prion protein of Ovis aries

Рис. 2. Выравнивание нуклеотидных последовательностей гена PRNP нормального $\operatorname{PrP}^{c}$ и патогенного $\operatorname{PrPsc}^{\mathrm{sc}}$ прионного белка Ovisaries

Поэтому в данном случае была выбрана разновидность ПЦР - метод иммуно-ПЦР в реальном времени для детекции инфекционных прионных белков, где молекулу ДНК используют в качестве маркера.

В ходе анализа было выбрано мышиное моноклональное антитело 15B3 (компании «Prionics»), которое получено с помощью 3-х различных последовательностей (эпитопа) пептида $\operatorname{PrP}$ человека: $15 \mathrm{~b} 3-1$ включает в себя аминокислотные остатки 142-148 GSDYEDR(YY); 15b3-2 остатки 162-170 YYRPVDQYS; 15b3-3 остатки 214-226 CITQYQRESQAYY (рисунок 3).

Компанией «Prionics» экспериментально установлено, что $15 \mathrm{~B} 3$ реагирует с патогенными $\mathrm{PrP}^{\mathrm{Sc}}$ прионами
It is not possible to select DNA target out of prion sequences for further analysis by PCR.

Therefore, in this case, modified PCR was selected the real-time immuno-PCR technique for detection of infectious prion protein, where the DNA molecule was used as a marker.

During the analysis, 15B3 murine monoclonal antibody was chosen (by Rrionics), which was obtained using 3 different sequences (epitopes) of human PrP peptide: 15b3-1 includes amino acid residues 142-148 GSDYEDR(YY); 15b3-2 includes amino acid residues 162-170 YYRPVDQYS; 15b3-3 includes amino acid residues 214-226 CITQYQRESQAYY (Figure 3).

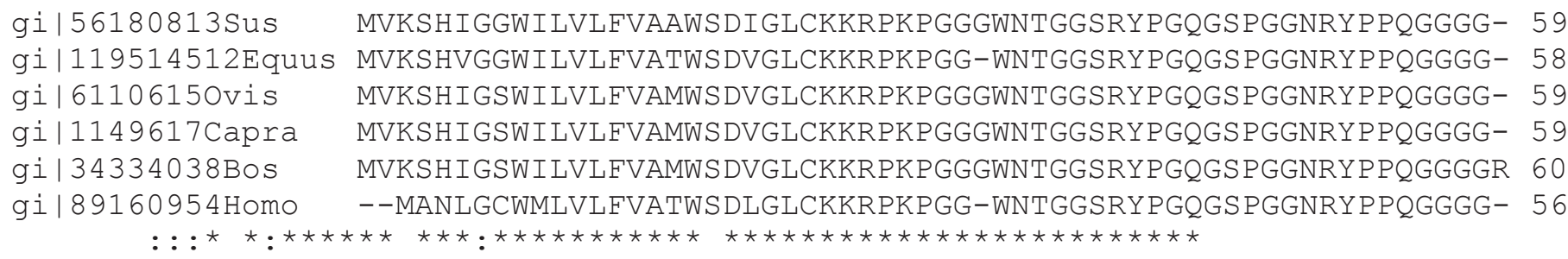

gi|56180813Sus -------WGQPHGGGWGQPHGGGWGQPHGGGWGQPHGGGGWGQGGGSHGQWNKPSKPKTN 112

gi|119514512Equus -------WGQPHGGGWGQPHGGGWGQPHGGGWGQPHGGGGWGQGG-SHGQWNKPSKPKTN 110

gi|61106150vis

gi|1149617Capra

gi|34334038Bos

gi 89160954 Homo -WGQPHGGGWGQPHGGGWGQPHGGGWGQPHGGGGWGQGG-SHSQWNKP SKPKTN 111 -------WGQPHGGGWGQPHGGGWGQPHGGGWGQPHGGGGWGQGG-SHSQWNKP SKPKTN 111 GQP HGGGWGQPHGGGWGQPHGGGWGQPHGGGWGQPHGGGGWGQGG-THGQWNKP SKPKTN 119 - - - - - WGQPHGGGWGQPHGGGWGQPHGGGWGQPHGGG-WGQGGGTHSQWNKP SKPKTN 108

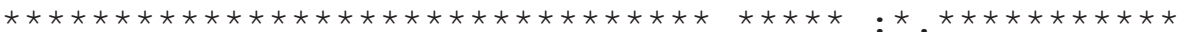

gi| 56180813 Sus gi|119514512Equus gi|61106150vis gi|1149617Capra gi|34334038Bos gi| 89160954 Homo MKHVAGAAAAGAVVGGLGGYMLGSAMSRPL I HFGSDYEDRYYRENMYRYPNQVYYRPVDQ MKHVAGAAAAGAVVGGLGGYMLGSAMSRPL I HFGNDYEDRYYRENMYRYPNQVYYRPVNF MKHVAGAAAA GAVVGGLGGYMLGSAMSRPL I HFGNDYEDRYYRENMYRYPNQVYYRPVDQ MKHVAGAAAAGAVVGGLGGYMLGSAMSRPLMHFGNDYEDRYYRENMYRYPNQVYYRPVDQ MKHVAGAAAAGAVVGGLGGYMLGSAMSRPL I HFGSDYEDRYYRENMHRYPNQVYYRPVDQ MKHMAGAAAA GAVVGGLGGYMLGSAMSRP I I HFGSDYEDRYYRENMHRYPNQVYYRPMDE

Figure 3. The amino acid sequence of PRNP prion protein gene

Рис. 3. Аминокислотная последовательность гена PRNPприонного белка 
Table 1. Parameters of primers | Таблица 1 - Параметры праймеров

\begin{tabular}{|c|c|c|c|c|c|}
\hline $\begin{array}{l}\text { Type of the primer | } \\
\text { Вид праймера }\end{array}$ & $\begin{array}{c}\text { Start position, bps | } \\
\text { Стартовая позиция, п.н }\end{array}$ & CG, \% & $\begin{array}{l}\text { Length, bps | } \\
\text { Длина, п.н. }\end{array}$ & $\mathbf{t}_{\mathrm{m}},{ }^{\circ} \mathrm{C}$ & Sequence | Последовательность \\
\hline Left | Левый & 41 & 55 & 20 & 60.25 & AGTCAGTCCTTGGCCTCCTT \\
\hline Right | Правый & 193 & 55 & 20 & 59.80 & CAGTTTCGATCCTCCTCCAG \\
\hline
\end{tabular}

Table 2. Scheme of amplification | Табл. 2. Схема проведения амплификации

\begin{tabular}{|c|c|c|c|}
\hline Operation | Операция & $\begin{array}{l}\text { Temperature, }{ }^{\circ} \mathrm{C} \mid \\
\text { Tемпература, }{ }^{\circ} \mathrm{C}\end{array}$ & $\begin{array}{c}\text { Duration, } \mathbf{~} \mid \\
\text { Продолжительность, c }\end{array}$ & $\begin{array}{l}\text { Number of cycles | } \\
\text { Количество циклов }\end{array}$ \\
\hline Pre-denaturation | Предварительная денатурация & 95 & 60 & 1 \\
\hline Denaturation | Денатурация & 95 & 30 & \multirow{3}{*}{30} \\
\hline Annealing | Отжиг & 56 & 60 & \\
\hline Elongation | Элонгация & 72 & 30 & \\
\hline Elongation | Элонгация & 72 & 600 & 1 \\
\hline
\end{tabular}

человека, крупного рогатого скота, овцы, оленя, мыши и хомяка, но не реагирует с нормальными $\operatorname{PrP}^{\mathrm{C}}$ прионами. Поэтому 15В3 может использоваться в качестве детектирующего антитела для дальнейшего анализа.

Построена синтетическая последовательность, длиной 194 п.н., полученная случайным образом (ДНК-хвост). Анализ в GenBank с помощью программы «BLAST» показал, что созданная последовательность и последовательности базы данных гомологов не имеют. К синтезированному ДНК-хвосту подобраны 2 праймера размерами 20 п.н.

C помощью программы «Primer3» подобраны параметры для соответствующих праймеров (таблица 1).

Полученные экспериментальные данные указывают на то, что при использовании праймеров AGTCAGTCCTTGGCCTCCTT (левого) и CAGTTTCGATCCTCCTCCAG (правого) амплификацию следует проводить по схеме, представленной в таблице 2 .

Для подбора оптимального состава реакционной смеси ПЦР был использован набор для оптимизации ПЦР — «PCROptimizationKitII» фирмы «Sigma».

В ходе работы были апробированы 10 буферных систем, которые различались концентрацией хлористого калия и величиной рН. Состав буферных систем приведен в таблице 3.

По завершению наработки кДНК полученные пробы детектировали электрофорезом в 2\%-ном агарозном геле, приготовленном на ТБЕ буфере в присутствии бромистого этидия. Полученные результаты представлены на рисунке 4.

Из полученных результатов следует, что при использовании буферных систем №6, 7 и 10 не происходит амплификации фрагмента. При использовании остальных буферных систем (№ 1, 2, 3, 4, 5, 8 и 9) нарабатывается ПЦР-продукт размером 153 п.н., представленный на рисунке 3.15 яркими и четкими полосами. Существенных различий при использовании буферных систем (№1, 2, 3, 4, 5, 8 и 9) не наблюдается.

Учитывая вышеприведенные факты, были приняты следующие компоненты ПЦР-реакции в концентрациях, указанных в таблице 4.
The Rrionics company experimentally established that 15B3 reacts with pathogenic $\mathrm{PrP}^{\mathrm{Sc}}$ prions of human, cattle, sheep, deer, mouse and hamster but does not react with normal $\mathrm{PrP}^{\mathrm{C}}$ prions. Therefore, 15B3 may be used as detection antibody for further analysis.

The synthetic sequence of 194 bps was randomly produced (DNA-tail). GenBank analysis using the BLAST software showed that the produced sequence and database sequences have no homologues. Two primer of $20 \mathrm{bps}$ were selected for synthesized DNA-tail.

Parameters for the respective primers were selected using Primer3 software (Table 1).

The experimental data indicate that, by using AGTCAGTCCTTGGCCTCCTT (left) and CAGTTTCGATCCTCCTCCAG (right) primers, amplification should be performed according to the scheme presented in Table 2 .

The kit for optimization of PCR, PCROptimizationKitII by Sigma company, was used for the selection of the optimal composition of the PCR reaction mixture.

During the work, 10 buffer systems were tested, which varied in concentration of potassium chloride and in $\mathrm{pH}$ level. The composition of buffer systems is given in Table 3.

Upon completion of cDNA production, the obtained samples were detected by electrophoresis in $2 \%$ agarose gel prepared with TBE buffer in the presence of ethidium bromide. The results are shown in Figure 4.

The results show that, by using the buffer systems No. 6, 7 , and 10 , there was no amplification of the fragment. When using the other buffer systems (No. 1, 2, 3, 4, 5, 8, and 9) PCR product of 153 bps was produced, which is shown in Figure 3.15 by bright and clear bands. No significant differences were observed when using different buffer systems (No. 1, 2, 3, 4, 5, 8, and 9).

Considering the above facts, the following components were used in PCR reaction at concentrations indicated in Table 4.

Thus, based on the studies, the components for PCR reaction were selected; the optimal parameters for amplification process were chosen; the composition of the reaction mixture for PCR reaction was determined. The positive control sample was experimentally obtained, which is 


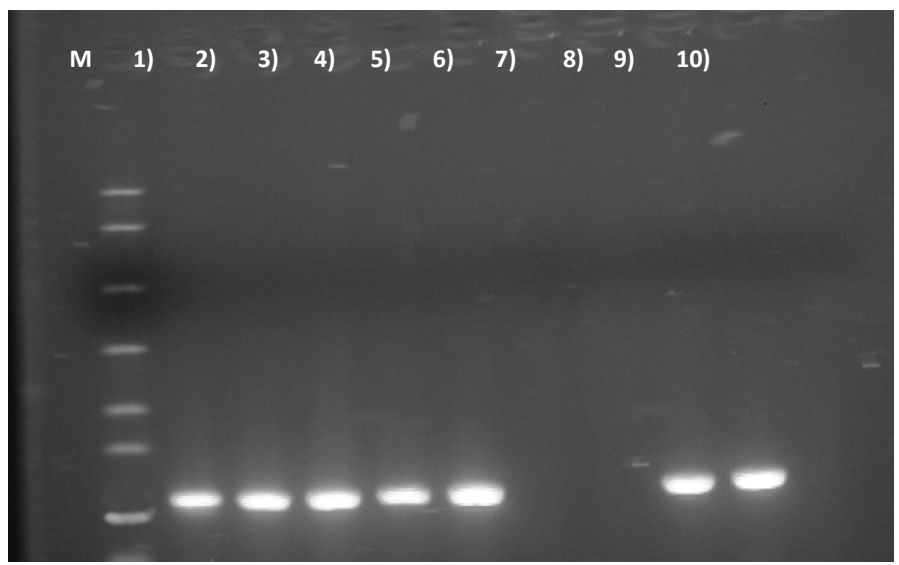

Figure 4. Electrophoregram of amplified specific region in various modes and buffer systems. M - DNA marker; 1) - 10) number of buffer systems

Рис. 4. Электрофореграммаамплифицированного специфичного участка в различных буферных системах и режимах. $\mathrm{M}$ - маркер ДНК; 1) - 10) номера буферных систем

Таким образом, на основании проведенных исследований подобраны компоненты для проведения ПЦР-реакции, выбраны наиболее оптимальные параметры процесса амплификации, установлен состав реакционной смеси для проведения ПЦР-реакции. Экспериментально получен положительный контрольный образец, являющийся маркером длины ПЦРпродуктов, обеспечивающий высокую чувствительность определения видовой специфичности тканей животного происхождения.

Подтверждена высокая специфичность разработанной тест-системы и олигонуклеотидныхпраймеров путем электрофоретического разделения образцов мясного фарша, содержащего патогенный прионный белок, а также путем сравнительного анализа результатов определения патогенного прионного белка, полученных с помощью ПЦР-тест-системы и ИФА-системы «TeSeE ${ }^{\text {тм }}$.

\section{Выводы}

Таким образом, на основании проведенных исследований выбрана высокопроизводительная ДНК-мишень; сконструированы два праймера, отвечающие требова-
Table 3. The composition of buffer systems used in the optimization of the PCR reaction mixture

Табл. 3. Состав буферных систем, используемых при оптимизации состава реакционной смеси ПЦР

\begin{tabular}{|c|c|}
\hline $\begin{array}{l}\text { Buffer No. | } \\
\text { № буфера }\end{array}$ & $\begin{array}{l}\text { The composition of PCR buffer, } \times 10 \mid \\
\text { Состав ПЦР буфера, } \times 10\end{array}$ \\
\hline 1 & $\begin{array}{l}100 \text { mM Tris-HCl, pH 8.3, } 250 \text { mM KCl| } \\
100 \text { мМТрисHCl, pH 8,3, } 250 \text { мMKCl }\end{array}$ \\
\hline 2 & $\begin{array}{c}100 \text { mM Tris-HCl, pH 8.3, } 750 \text { mM KCl | } \\
100 \text { мМТрисHCl, pH 8,3, } 750 \text { мMКCl }\end{array}$ \\
\hline 3 & $\begin{array}{l}50 \text { mM Tris- } \mathrm{HCl}, \mathrm{pH} \mathrm{8.3,250} \mathrm{mM} \mathrm{KCl|} \\
50 \text { мМТрисHCl, pH 8,3, } 250 \mathrm{mMKCl}\end{array}$ \\
\hline 4 & $\begin{array}{l}50 \mathrm{mM} \text { Tris-HCl, pH 8.3, } 750 \mathrm{mM} \mathrm{KCl} \mid \\
50 \text { мМТрисHCl, pH 8,3, } 750 \mathrm{mMKCl}\end{array}$ \\
\hline 5 & $\begin{array}{l}100 \text { mM Tris-HCl, pH 8.8, } 250 \text { mM KCl| } \\
100 \text { мМТрисHCl, pH 8,8, } 250 \text { мMKCl }\end{array}$ \\
\hline 6 & $\begin{array}{c}100 \text { mM Tris-HCl, pH 8.8, } 750 \text { mM KCl| } \\
100 \text { мMТрисHCl, pH 8,8, } 750 \text { мMKCl }\end{array}$ \\
\hline 7 & $\begin{array}{l}50 \mathrm{mM} \text { Tris-HCl, pH 8.8, } 250 \mathrm{mM} \mathrm{KCl} \mid \\
\text { 50MM TрисHCl, pH 8,8, } 250 \mathrm{MMKCl}\end{array}$ \\
\hline 8 & $\begin{array}{l}50 \mathrm{mM} \text { Tris- } \mathrm{HCl}, \mathrm{pH} \mathrm{8.8,750} \mathrm{mM} \mathrm{KCl|} \\
50 \mathrm{MM} \mathrm{TрисHCl,} \mathrm{pH} \mathrm{8,8,} 750 \mathrm{MMKCl}\end{array}$ \\
\hline 9 & $\begin{array}{c}100 \text { mM Tris-HCl, pH 9.2, } 250 \text { mM KCl | } \\
100 \text { мMТрисHCl, pH 9,2, } 250 \text { мMKCl }\end{array}$ \\
\hline 10 & $\begin{array}{c}100 \text { mM Tris-HCl, pH 9.2, } 750 \text { mM KCl| } \\
100 \text { мМТрисHCl, pH 9,2, } 750 \text { мMКCl }\end{array}$ \\
\hline
\end{tabular}

a marker for the length of PCR product that provides high sensitivity for determination of animal tissues species.

High specificity of the developed test system and of oligonucleotide primers was confirmed by electrophoretic separation of ground beef samples containing pathogenic prion protein and by comparative analysis of determination results of pathogenic prion protein obtained by PCRtest system and TeSeE ${ }^{\mathrm{rx}}$ ELISA system.

\section{Conclusions}

Thus, based on the studies, high performance DNA target was selected; two primers were designed to meet the requirements for PCR reaction; the optimal denatur-

Table 4. Composition of PCR reaction mixture

Табл. 4. Состав реакционной смеси ПЦР

$$
\text { Component | Компонент }
$$

10X PCR buffer | 10X ПЦР-буфер

10 mM dNTP mix | 10мМ смесь дНТФ

Primer 1 (50 uM) | Праймер 1 (50 мкM)

Primer 2 (50 uM) | Праймер 2 (50 мкM)

Taq-DNA polymerase | Taq-ДНК-полимераза

$25 \mathrm{mM} \mathrm{MgCl}_{2} \mid 25 \mathrm{MM} \mathrm{MgCl}_{2}$

DNA template | ДНК-матрица

Deionized water | Деионизированная вода
Final concentration | Конечная концентрация 1X $\mid 1 \mathrm{X}$ $0.2 \mathrm{mM}$ each | 0,2 мМ каждого 1 uM | 1 мкM 1 uM | 1 мкM $1.25 \mathrm{U} \mid 1,25$ ед. $1.5 \mathrm{mM} \mid 1,5 \mathrm{MM}$

0.1-1 ug | 0,1-1 мкг
Amount of component per $25 \mathrm{uL}$ of mixture | Количество компонента на 25 мкл смеси

$$
\begin{gathered}
2.5 \mathrm{uL} \mid 2,5 \text { мкл } \\
0.5 \mathrm{uL} \mid 0,5 \text { мкл } \\
0.5 \mathrm{uL} \mid 0,5 \text { мкл } \\
0.5 \mathrm{uL} \mid 0,5 \text { мкл } \\
0.25 \mathrm{uL} \mid 0,25 \text { мкл } \\
1 \mathrm{uL} \mid 1 \text { мкл }
\end{gathered}
$$

varies depending on the concentration of the sample | варьируется от концентрации образца Up to $25 \mathrm{uL}$ | До 25 мкл 
ниям для проведения ПЦР, определена оптимальная температура денатурации и отжига при использовании двух праймеров, установлена концентрация компонентов реакционной смеси для проведения ПЦР. Наибольшую активность ПЦР-тест-система сохраняет при температуре хранения $(4 \pm 2){ }^{\circ} \mathrm{C}$ и через четыре месяца хранения она составляет 99,8\%. В пределах исследуемого периода (4 месяца) разработанная ПЦР-тест-система характеризуется высокой чувствительностью и может быть использована для эффективной идентификации патогенного прионного белка в животных тканях.

Работа выполнена в рамках федеральной целевой программы «Исследования и разработки по приоритетным направлениям развития научно-технического комплекса России» по теме «Разработка и применение молекулярно-генетических методов для идентификации и типирования возбудителей инфекционных болезней животных», государственный контракт № 16.512.11.2077. ation and annealing temperature was determined using two primers; the concentration of $\mathrm{PCR}$ reaction mixture components was determined. The activity of PCR test system is highest at a storage temperature of $4 \pm 2{ }^{\circ} \mathrm{C}$ and after four months of storage it is $99.8 \%$. Within the test period (4 months) the developed PCR test system is characterized by high sensitivity and can be used for effective identification of pathogenic prion protein in animal tissues.

The work was carried out within the framework of the federal target program «Research and development in priority areas of scientific and technical complex in Russia» on the topic «Development and application of molecular and genetic methods for identification and typing of pathogens inducing the animal infectious diseases,» state contract No. 16.512.11.2077.
БИБЛИОГРАФИЧЕСКИЙ СПИСОК

1. Кригер, О.В. Прионные инфекции: характеристика возбудителей и способов диагностики трансмиссивных губчатых энцефалопатий крупного рогатого скота / О.В. Кригер, О.В. Козлова, А.Ю. Просеков // Вестник НГАУ. - 2011. - № 3. - С. 85-89.

2. Мудрикова, О.В.Исследование содержания нормального прионного белка крупного рогатого скота в пробах биологического происхождения / О.В. Мудрикова, О.В. Кригер, А.Ю. Просеков, А.Р. Хананова, С.Ю. Гармашов // Аостижения науки и техники АПК. - 2011. - № 11. - С. 77-79.

3. Кригер, О.В. Основные аспекты конструирования праймеров Аия определения видовой принадиежности АНК крупного рогатого скота методом полимеразной цепной реакции / О.В. Кригер, А.С. Солдатова, А.Ю. Кравченко, М.В. Новоселова // Современные проблемы науки и образования. - 2012. - № 2. - С. 362. 4. Арагунова, Е.Е. ПЦР-тест-система Ая идентификации патогенного прионного белка: необходимость разработки, методика изготовления и основные характеристики / Е.Е. Арагунова, И.С. Милентьева, О.В. Кригер, М.В. Новоселова // Фундаментальные исследования. - 2013. - № 10. - Часть 8. - С. 1739-1740. 5. Москвина, Н.А. Применение метода полимеразной цепной реакции Аяя видовой идентификации продуктов переработки растительного сырья / Н.А. Москвина, Ю.В. Голубцова, О.В. Кригер // Техника и технология пищевых производств. 2014. - № 2. - С. 126-129.

6. Арагунова, Е.Е. Филогенетический анализ степени эвамюционного родства последовательностей прионного белка / Е.Е. Арагунова, И.С. Милентьева, О.В. Кригер, М.В. Новоселова // Пищевые инновации и биотехнологии: материалы международного научного форума. - Кемерово, 2013. - С. 172-180. 7. Москвина Н.А АНК-маркеры, основанные на полимеразной цепной реакции - как метод оценки гигиенического разнообразия плодово-ягодного сырья / Н.А. Москвина, Ю.В. Голубцова, А.С. Аышлюк, А.Ю. Просеков // Теоретические и прикиадные аспекты современной науки. - 2015. - № 7-1. - С. 134-137. 8. Просеков А.Ю. Разработка прототипов молекулярно-гинетических тест-систем Аия выявления и типирования прионоВых инфекций / А.Ю. Просеков, О.О. Бабич, М.В. Новоселова // В сборнике: Международная научно-практическая конференция Биотехнология и качество жизни: материалы международной научно-практической конференции. Москва, 2014. - С. 577-578. 9. Просеков А.Ю. Влияние технологической обработки продовольственного сырья на эффективность видовой идентификации / А.Ю. Просеков, Ю.В. Голубцова, К.А. Шевякова // Пищевая промышленность. - 2014. - № 6. - С. 8-10.

10. Просеков А.Ю. Исследование состава и свойств белков животного происхожАения биологических объектов и молочных продуктов многокомпонентного состава / Просеков А.Ю., Позднякова А.В. // Вестник Красноярского государственного аграрного университета. - 2014. - № 8. - С. 101-107.

\section{REFERENCES}

1. Kriger, 0.V. Prion infection: characterization of pathogens and methods for the diagnosis of transmissible spongiform encephalopathies in cattle / 0.V. Krieger, O.V. Kozlova, A.Y .Prosekov // Herald NGAU. - 2011. - № 3. - P. 85-89.

2. Mudrikova, O.V.Issledovanie content of the normal prion protein in cattle in samples of biological origin / O.V Mudrikova, O.V. Kriger, A.Y Prosekov, A.R Hananova, S.Y Garmashov // Advances in science and agribusiness technology. - 2011. № 11. - P. 77-79.

3. Kriger, $0 . v$ The main aspects of designing primers for certain types of DNA supplies of cattle using polymerase chain reaction / O.V Krieger, L.S Soldatov, A.Y Kravchenko M.V Novoselova // Modern problems of science and education. - 2012. - № 2. P. 362.

4. Dragunova, E.E PCR test system for the identification of pathogenic prion protein: the need to develop, manufacture technique and the basic characteristics / E.E Dragunova, I.S. .Milentyeva, O.V. Kriger, M. Novoselova // Basic Research. - 2013. № 10. - Part 8. - C. 1739-1740.

5. Moskvina, N.A. Application of polymerase chain reaction for species identification products processing plant raw materials N.A. Moskvina, Y. Golubtsova, O.V. Kriger // Engineering and technology of food production. - 2014. - № 2. - P. 126-129. 6. Dragunova, E.E. Phylogenetic analysis of the degree of kinship evalyutsionnogo sequences of prion protein / E.E. Dragunova, I.S. Milentyeva, O.V. Kriger, M. Novoselova // Food and Biotechnology Innovation: Proceedings of the international scientific forum. - Kemerovo, 2013. - P. 172-180.

7. N.A. Moskvina DNA markers based on polymerase chain reaction - as a method of assessing the hygienic variety of fruit raw material / N.A. Moskvina, Y. Golubtsova, L.S .Dyshlyuk, A.Y. Prosekov // Theoretical and applied aspects of modern science. - 2015. - № 7-1. - P. 134-137.

8. Prosekov A.Y. Prototyping gineticheskih molecular test kits for the detection and typing of prion infections / A.Y. Prosekov, 0.0. Babich, M. Novoselova // In: International Scientific-Practical Conference Biotechnology and quality of life: the materials of the international scientific-practical conference. Moscow 2014. - P. 577-578.

9. Prosekov A.Y. Influence of processing food raw materials on the effectiveness of specific identification / A.Y. Prosekov, Y. Golubtsova, K.A. Shevyakova // Food Industry. - 2014. - № 6. P. 8-10.

10. A.Y. Prosekov The study of composition and properties of proteins of animal origin of biological objects and dairy products multicomponent composition / Prosekov A.Y, Pozdnyakova A.V . // Bulletin of the Krasnoyarsk State Agrarian University. 2014. - № 8. - P. 101-107. 


\section{СВЕДЕНИЯ ОБ АВТОРАХ}

Принадлежность к организации

Просеков Александр Юрьевич - доктор технических наук, профессор, и. о. ректора «Кемеровского государственного университета», заведующий кафедрой «Бионанотехнология», ФГБОУ ВО «Кемеровский технологический институт пищевой промышленности (университет)»

650056, г. Кемерово, бульвар Строителей, 47

Тел.: 8-3842-39-05-37

E-mail: bionano_kem@mail.ru

Кригер Ольга Владимировна - кандидат технических наук, доцент, доцент кафедры «Бионанотехнология», ФГБОУ ВО «Кемеровский технологический институт пищевой промышленности (университет)»

650056, г. Кемерово, бульвар Строителей, 47,

Тел.: 8-3842-39-05-37

E-mail: bionano_kem@mail.ru

\section{Критерии авторства}

Авторы в равных долях имеют отношение к написанию рукописи и одинаково несут ответственность за плагиат.

Конфликт интересов

Авторы заявляют об отсутствии конфликта интересов.

Поступила 12.09.2016

\section{AUTOR INFORMATION}

Affiliation

Prosekov Alexander Yurievich -Dr. Sci. (Eng.), Professor, Acting President of the Kemerovo State University, Head of the Department of bionanotechnology, FSBEI HVE «Kemerovo Institute of Food Science and Technology»

47, Boulevard Stroiteley, Kemerovo, 650056, Russia

Tel.: 8-3842-39-05-37

E-mail: bionano_kem@mail.ru

Kriger Olga Vladimirovna - Ph.D., Associate Professor, Department of bionanotechnology, FSBEI HVE «Kemerovo Institute of Food Science and Technology»

47, Boulevard Stroiteley, Kemerovo, 650056, Russia

Tel.: 8-3842-39-05-37

E-mail: bionano_kem@mail.ru

\section{Contribution}

The authors equally contributed to the writing of the manuscript and are equally responsible for plagiarism.

\section{Conflict of interest}

The authors declare no conflict of interest.

Received 12.09.2016 